Visualizing Objects, Places, and Spaces: A Digital Project Handbook

\title{
Documentation for Archival Projects
}

Beth Fischer, Hannah Jacobs, Claire Cahoon, Noah Huffman

Published on: Oct 14, 2019

DOI: $10.21428 / 51$ bee781.c9e0b9b3

License: Creative Commons Attribution 4.0 International License (CC-BY 4.0). 


\section{Documentation for an archival project should cover at least three areas:}

1. The goals and parameters of the project. This can be made at the outset, though it may need to be revised. This helps avoid having the project expand or diverge from its original goals, which can add expense, time, and ruin the fit of the tools and organization scheme. This can be as simple as a few sentences or paragraphs describing what material will be included, who the end users will be, and what they should get out of the archive. This might be a summary of the work you do in the planning phase. Use this description regularly to help make decisions about your content as you work.

\section{The decisions that are made about how the content is processed and} organized. This is very project specific, but it should include at minimum descriptions of the format for each field or record, any specific vocabulary or terminology, and any rules about how to deal with missing data or data that is unverified. Looking up controlled vocabulary examples for your field or the can give you examples of the way these descriptions might look. This should help you be specific about things like the format for dates, and whether you include middle names, or whether states are entered in as two-letter abbreviations. You might keep this in a single shared document, or some programs have places for field instructions directly within your information storage structure.

\section{A "diary" or logbook of current status points, any issues you run into and} how they were resolved, and ideas you want to hold onto for later use or use to keep team members informed. This can be as simple as a shared word document in reverse date order, with each person who works on the project entering the date and some bullet points. You might include bullets like "entered objects 5074; object 66 and 69 are missing dates" or "scanned photos from Book for section on Singapore in the 1960s, used settings $\mathrm{x}, \mathrm{y}$, and $\mathrm{z}$ and saved as tifs in folder A." While this record is intended for your internal project team, remember that you may need to consult it months or years later, or may need to search for notes in a long document, so you want to be clear and complete. If the project is complex or different people have ownership of different parts, you may want a more structured format or to create a status spreadsheet or other project management form as well. 


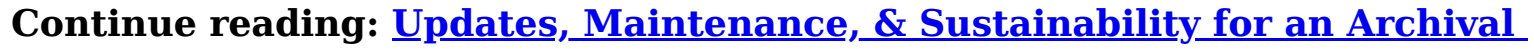
Project 